\title{
The protein quality of mycoprotein
}

\author{
D. G. Edwards ${ }^{1}$ and J. H. Cummings ${ }^{2}$ \\ ${ }^{1}$ Gareth Edwards Consultancy, 63 Woodlands Road, Sonning Common, RG4 9TD, UK and ${ }^{2}$ Division of Medical Sciences, \\ Ninewells Hospital and Medical School, Dundee DDI 9SY, UK
}

Mycoprotein is a food ingredient produced by the continuous fermentation of Fusarium venenatum on a carbohydrate substrate and whose RNA content has been reduced. Mycoprotein is the main ingredient in a range of foods sold under the Quorn $\mathrm{TM}$ brand and has been available in the United Kingdom since 1985. Many of these products can form the central part of a main meal, so the protein they provide is likely to be significant for some individuals, particularly for high consumers.

Bioassays, such as NPU and PER, have indicated a protein quality similar to milk protein ${ }^{(1)}$ and this was confirmed in a study involving healthy male subjects, where mycoprotein was shown to have a biological value equivalent to milk and superior to it when supplemented with methionine $e^{(2)}$. In this study, the apparent protein digestibility of $78 \%$ was likely to have been an underestimate, because the fibre in mycoprotein contributes non-protein nitrogen from chitin (n-acetyl glucosamine).

In a study at the Dunn Clinical Nutrition Centre, Cambridge, the digestibility of mycoprotein in the small bowel of 5 female ileostomy subjects was unaffected by steaming, baking, frying or microwaving. The results, including energy and minerals, are summarised below along with a brown bread control.

\begin{tabular}{lrcccccccccccccc}
\hline & & \multicolumn{1}{c}{ Ileal digestibility (\%) } \\
\cline { 2 - 9 } & $N$ & Nitrogen & SD & Energy & SD & Calcium & SD & Magnesium & SD & Iron & SD & Zinc & SD \\
\hline Mycoprotein & 14 & 89.8 & 2.6 & 90.9 & 2.1 & 29.5 & 9.4 & 42.1 & 11.0 & 49.8 & 10.6 & 24.4 & 9.1 \\
Bread & 5 & 98.7 & 2.6 & 91.6 & 2.1 & 28.3 & 8.7 & 42.8 & 10.8 & 40.5 & 12.1 & 23.8 & 13.9 \\
\hline
\end{tabular}

Methionine and cysteine are the first limiting amino acids in mycoprotein and using the above nitrogen digestibility figure to calculate the protein digestibility corrected amino acid score (PDCAAS) ${ }^{(3)}$ gives a value in excess of 1.0. However, the analytical data suggested that around $10 \%$ of the glucosamine nitrogen may have been digested in the small intestine, although this was not certain since intestinal mucus contains some glucosamine which may have contributed to this apparent effect. Therefore, the true protein digestibility may have been a little lower at around $86 \%$. Using this more cautious figure gives a PDCAAS of 0.996 , confirming the high protein quality of mycoprotein.

1. Edwards DG (1993) Int J Food Sci Nutr 44 (Suppl. 1), 537-543.

2. Udall JN, Lo CW, Young VR et al. (1984) Am J Clin Nutr 40, 285-292.

3. WHO (2007) Protein and amino acid requirements in human nutrition. Report of a Joint WHO/FAO/UNU Expert Consultation, Geneva. World Health Organisation (Technical Report Series No. 935). 